\title{
Effect of Hemodialysis on Trace Elements in Renal Failure Patients
}

\author{
Anusha P Dsouza ${ }^{1}$, Ramlinga Reddy ${ }^{2}$, Anurag Yadav ${ }^{3}$, Malathi Mala ${ }^{4}$
}

\begin{abstract}
Hemodialysis patients are at prone for essential trace element deficiency and accumulation of excess harmful trace elements, together of which can affect health burden. During dialysis required renal functions, such as the removal of metabolic waste products, water, correction of the acid-base status and electrolytes are substituted by the artificial purification system. Prone for both accumulation and deficiency of trace elements depends on removal by dialysis, dietary intake, the content of the source water used for dialysis and residual kidney function. This study aimed to evaluate the possible changes in serum iron ( $\mathrm{Fe}$ ) and zinc ( $\mathrm{Zn}$ ) levels in CRF patients undergoing dialysis, pre, and post. It is a case-control hospital-based study $(n=90)$, Patients included in the present study were all admitted to the Nephrology unit or attending the outpatient department of Nephrology and Dialysis ward. Group IA- Pre-hemodialysis, Group IB- Post-haemodialysis, Group II- Normal healthy controls. Results showed serum zinc levels in both groups of CRF patients (IA, IB) were significantly higher when compared to controls. There was a significantly higher serum level of iron in Group-IB when compared to Group-1A patients. To conclude, the present study has observed significant changes in zinc and iron in CRF patients, pre- and post-hemodialysis.
\end{abstract}

Keywords: Chronic renal failure, Hemodialysis, Iron, Zinc.

Indian Journal of Medical Biochemistry (2019): 10.5005/jp-journals-10054-0093

\section{INTRODUCTION}

Hemodialysis patients are at prone for deficiency of essential trace elements and accumulation of excess toxic trace elements, both of which can affect health and disease. Hemodialysis is the most common form of treatment for end-stage kidney disease. ${ }^{1}$ Chronic renal failure (CRF) is a clinical syndrome, which leads to progressive and irreversible destruction of nephrons. The destruction leads to a reduction of glomerular filtration rate (GFR). ${ }^{2}$ During dialysis required renal functions, such as the removal of metabolic waste products and water, correction of the acid-base status and electrolytes are substituted by the artificial purification system. ${ }^{3}$

Uremic toxins are removed primarily by allowing equilibration of plasma and dialysate across a semi-permeable membrane during hemodialysis. Substances with lower levels of concentration in dialysate than in plasma tend to be removed, in the case of uremic toxins; it may result in a deficiency of biologically important substances. Substances present in dialysate but not in the blood may tend to accumulate in the patient, and poor renal clearance in these patients might lead to toxicity of ingested trace elements even when they are not present in the dialysate. Thus, dialysis patients are at prone for both deficiency and accumulation of trace elements, depending on dietary intake, removal by dialysis and content of the source water used for dialysis, and residual kidney function. ${ }^{4}$ Depletion or disproportionate accumulation of trace elements are both known to have fatal consequences in the general population and may have clinically significant implications like increased risk for cardiovascular disease, anemia, cancer, immune deficiency, bone disease, and renal function impairment. But very little is known about trace element concentration with its metabolism and pathophysiology in normal healthy individuals and uremia patients. ${ }^{5}$

The altered trace element status (if present) would contribute to morbidity and mortality among hemodialysis patients. However, the occurrence of abnormal trace element status in hemodialysis patients has not been extensively studied. Therefore, a study was taken to evaluate the possible changes in serum iron (Fe) levels and zinc ( $\mathrm{Zn}$ ) in CRF patients undergoing hemodialysis.
${ }^{1}$ MBBS Student, ${ }^{2,3}$ Assistant Professor, ${ }^{4}$ Professor and Head

${ }^{1-4}$ Department of Biochemistry, Father Muller Medical College, Mangaluru, Karnataka, India

Corresponding Author: Ramlinga Reddy, Assistant Professor, Department of Biochemistry, Father Muller Medical College, Mangaluru, Karnataka, India, e-mail: ramlingreddy2020@yahoo.co.in

How to cite this article: Dsouza AP, Reddy R, Yadav A, Mala M. Effect of Hemodialysis on Trace Elements in Renal Failure Patients. Indian J Med Biochem 2019;23(2):233-235.

Source of support: Nil

Conflict of interest: None

\section{Aims And Objectives}

To estimate the serum levels of iron and zinc in chronic renal failure patients, pre and posthemodialysis in comparison to normal healthy controls

To assess the effect of hemodialysis on serum levels of iron and zinc in chronic renal failure patients, pre and posthemodialysis.

\section{Materials and Methods \\ Source of Data}

This is a case-control hospital-based study. The study was carried out in the Department of Biochemistry, Father Muller Medical College, Mangaluru. In this, patients included in the present study were all admitted to the Nephrology unit or attending the outpatient department (OPD) of Nephrology, and some patients were admitted to the Nephrology and Dialysis ward, Medical College Hospital, Mangaluru. The study group consisted of thirty chronic renal failure patients prehemodialysis (group IA) and thirty chronic renal failure patients post-hemodialysis (group IB), of both the sexes in the age ranging from $30-90$ years were admitted to hospital. All patients were dialyzed for $4 \pm 1$ hours per session with dialysis membrane by using Nipro dialysis machine which gets auto-calibrated for every dialysis session and also before every

(c) The Author(s). 2019Open Access This article is distributed under the terms of the Creative Commons Attribution 4.0 International License (https://creativecommons. org/licenses/by-nc/4.0/), which permits unrestricted use, distribution, and non-commercial reproduction in any medium, provided you give appropriate credit to the original author(s) and the source, provide a link to the Creative Commons license, and indicate if changes were made. The Creative Commons Public Domain Dedication waiver (http://creativecommons.org/publicdomain/zero/1.0/) applies to the data made available in this article, unless otherwise stated. 
dialysis session conductivity will be checked which should pass the normal conductivity criteria $(<1)$. Blood samples were obtained from the concerned subjects before dialysis (group IA) and after dialysis (group IB) for the study. The diagnosis was based on history, detailed clinical examination, and relevant laboratory investigations. Thirty healthy subjects (group II), age and gender-matched, having normal kidney functions (urea, creatinine) were included as controls. The study was conducted after getting approval from the institutional ethics committee and informed consent was obtained from all the participants.

\section{Inclusion Criteria}

- Group IA: Thirty, clinically diagnosed with chronic renal failure (CRF) patients prehemodialysis (age: 30-90 years; both males and females) admitted in Nephrology Unit of Medical College, Hospital.

- Group IB: Thirty, clinically diagnosed with chronic renal failure (CRF) patients post-hemodialysis (age: 30-90 years; both males and females) admitted in Nephrology Unit of Medical College, Hospital.

- Group II: 30, normal, healthy, age and sex-matched volunteers (age: $30-90$ years; both males and females)

\section{Exclusion Criteria}

Chronic alcoholic drinkers, chewers (tobacco), all smokers, pregnancy, systemic illness (infectious conditions, sepsis, malignancy, hepatobiliary diseases, cardiac diseases).

\section{Collection of Samples}

Five $\mathrm{mL}$ of the venous blood sample was drawn under all aseptic precautions from the concerned subjects, prehemodialysis

Table 1: Serum Levels of zinc and iron (values are mean \pm SD)

\begin{tabular}{llll}
\hline & $\begin{array}{l}\text { Group IA } \\
(n=30)\end{array}$ & Group IB $(n=30)$ & $\begin{array}{l}\text { Group II } \\
(n=30)\end{array}$ \\
\hline $\begin{array}{l}\text { Serum zinc } \\
(\mu \mathrm{g} / \mathrm{dL})\end{array}$ & $140.11 \pm 19.81^{*}$ & $147.59 \pm 17.73^{*}$ & $82.46 \pm 10.26$ \\
$\begin{array}{l}\text { Serum iron } \\
(\mu \mathrm{g} / \mathrm{dL})\end{array}$ & $69.79 \pm 22.91^{*}$ & $114.23 \pm 55.61^{*},{ }^{* *}$ & $85.10 \pm 27.36$ \\
\hline
\end{tabular}

*Significance of difference when compared to controls, $p<0.001$ **Significance of difference when compared to CRF before hemodialysis $p<0.001$

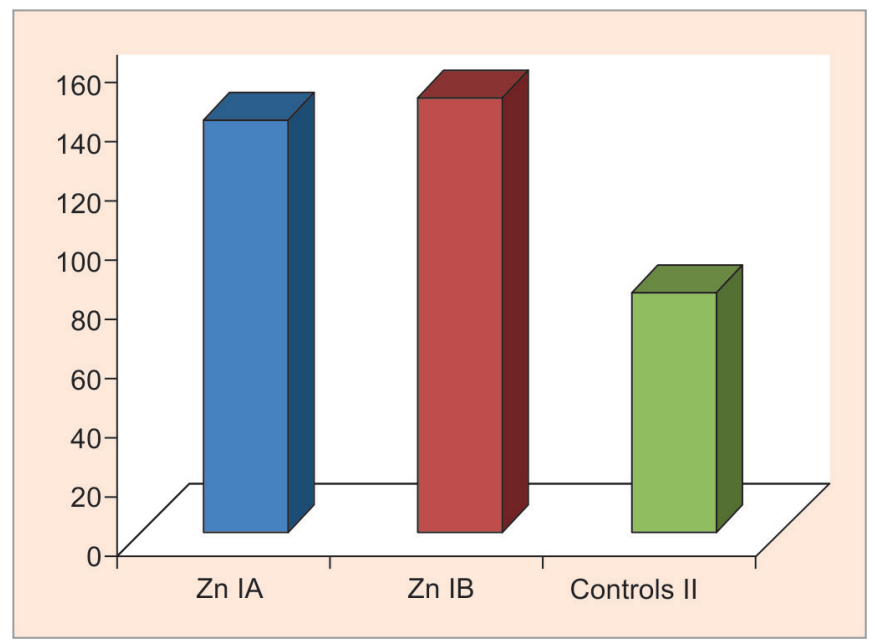

Graph 1: Serum zinc levels in group IA, IB, II ( $\mu \mathrm{g} / \mathrm{dL})$ (group IA) and post-hemodialysis (group IB) and healthy subjects (group II) for the study, and centrifuged at 3000 rpm for 15 minutes to serum for the assays of iron and zinc.

\section{Assay Done}

The entire assay done by standard spectrophotometric and colorimetric method. Assay of serum iron was done by using ferrozine method without deproteinization. ${ }^{6}$ Serum zinc by a spectrophotometric method using Nitro-PAPS reagent. ${ }^{7}$

\section{Statistical Analysis}

All statistical analyses were done by using statistical package for the social sciences (SPSS V.17.0). Continuous variables were analyzed by measures such as sample mean, standard deviation, and statistical significance was tested by independent sample T-test. Mann-Whitney and Kruskal-Wallis test was used to analyze the significance of the difference of values between the groups.

\section{Observations and Results}

Results of this study are presented in Table 1 and Graphs 1 and 2 . The subjects of the study were patients with chronic renal failure before hemodialysis (group IA; $\mathrm{n}=30$ ), chronic renal failure patients after hemodialysis (group IB; $\mathrm{n}=30$ ) and normal healthy controls (Group II; $\mathrm{n}=30$ ).

The serum levels of zinc in both groups of CRF patients (IA, IB) were significantly higher when compared to controls. There was a significant higher Serum level of iron in Group-IB when compared to Group-IA patients. A serum zinc level in group-IB is higher when compared to Group-IA patients which were nonsignificant.

\section{Discussion}

The present study made an attempt to assess serum levels of zinc and iron in patients with chronic renal failure before hemodialysis (group $I A ; n=30$ ) in comparison to chronic renal failure patients after hemodialysis (group IB; $\mathrm{n}=30$ ) and normal healthy controls (Group II; $n=30$ ). The serum zinc levels in both groups of CRF patients (IA, IB) were significantly higher compared to controls. There was a significantly higher serum iron level in group-IB when compared to group-IA patients. A serum level of zinc in group-IB is higher compared to Group-1A patients which were non-significant.

Studies have shown that there are alterations in the metabolic behavior of zinc in hemodialysis patients. In CRF, derangements

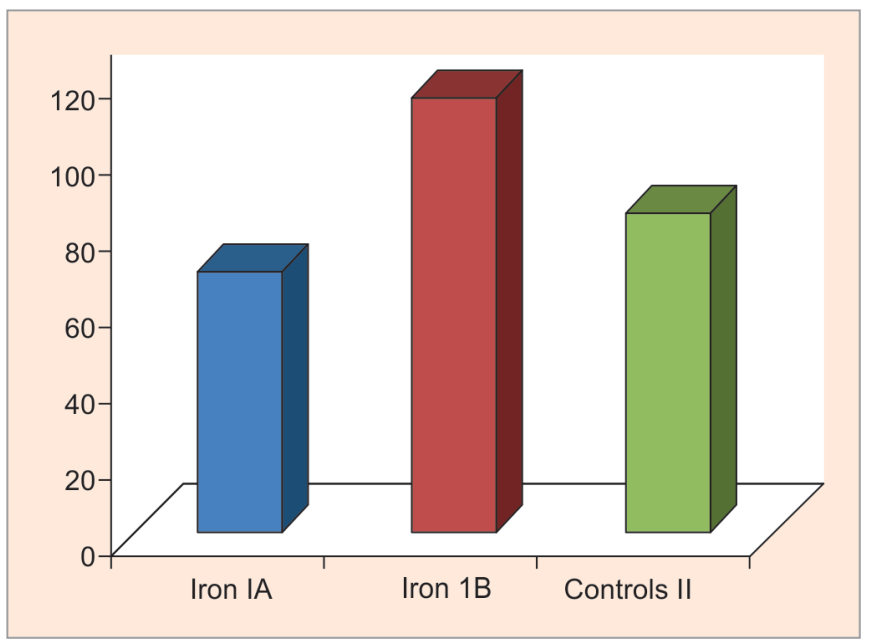

Graph 2: Serum iron levels in group IA, IB, II ( $\mu \mathrm{g} / \mathrm{dL})$ 
in zinc homeostasis may be found due to malabsorption of microelements in the gastrointestinal tract, altered protein metabolism, disturbed renal excretion and expected faulty tissue and cellular redistribution. ${ }^{8}$ In the present study serum levels of zinc in both groups of CRF patients (IA, IB) were significantly higher when compared to controls. A number of studies have reported that patients of chronic kidney disease (CKD) on HD have disturbed levels of trace elements. ${ }^{9,10}$ Contamination of the hemodialysis fluids and inability to remove these will result in deposition of the trace elements like zinc to toxic levels in the body. In endstage, renal disease patient's different conditions affect blood concentrations of zinc, like increased oral ingestion, degree of renal failure for excretion, use of medications, quality of water system used for dialysis and metabolic derangements associated with renal disease. Fatal, acute as well as chronic toxicities of serum zinc have been reported. ${ }^{10}$ To prevent these complications in chronic hemodialysis patients, it is imperative to regulate trace elements levels by adequate water treatment before dialysis. Most of the authors verify decreased serum levels of zinc in patients with CRF on conservative or dialysis treatment. ${ }^{11,12}$ while other authors find out elevated lymphocyte and erythrocyte zinc content. ${ }^{13}$ Few studies showed raised amounts of the majority trace elements in blood levels (zinc, boron, manganese, aluminum, chromium, copper, vanadium, cobalt, cadmium, strontium, lead \& barium) was observed for end-stage renal disease patients, in comparison with controls. ${ }^{13}$

A serum zinc level in group-IB was non-significantly higher when compared to group-IA patients. Tetiker et al.., ${ }^{14}$ says that there was no significant difference between $\mathrm{Zn}$ levels before and after in chronic dialysis patients. However, in a study performed by Paydas et al., ${ }^{15} \mathrm{Zn}$ levels found to be normal in chronic dialysis patients.

Iron is known to be toxic when accumulated in tissues due to its role in the generation of free radicals and induction of oxidative stress. Increased iron levels in the serum of humans with kidney disease suggest its possible role in the pathogenesis of chronic kidney disease patients on hemodialysis. ${ }^{16}$ In the present study serum, iron levels in groups IB were significantly higher when compared to controls and Group-1A patients. However, few studies have raised concern for tissue deposition of iron among dialysis patients. A study by Rostoker et al., ${ }^{17}$ in 119 hemodialysis patients demonstrated iron in tissue was analyzed by $\mathrm{T} 1$ and $\mathrm{T} 2^{*}$ contrast magnetic resonance imaging (MRI) without gadolinium which showed, mild hepatic iron overload was present in $84 \%$ of patients and severe in $36 \%$ respectively. The key roles of regulatory proteins, hepcidin, ferroportin, ferritin, and transferrin in iron regulation in the body and prevent free unbound form. ${ }^{17}$

Kooistra et al., ${ }^{18}$ demonstrated, iron sucrose $100 \mathrm{mg}$ in dialysis patients, showed TSAT raised to over $400 \%$, indicating oversaturation, with increased catalytically active iron in circulation. This clearly showed to induce oxidative stress and cytotoxicity in vitro, in normal human volunteers, animals, and in dialysis patients. Finally, even though of less relevance to hemodialysis patients, there have been reports of kidney toxic effects of iron, this could be related to free iron or oxidative damage. ${ }^{18}$

\section{Conclusion}

The present study has observed significant changes in iron and zinc in CRF patients before and after dialysis. The changes in these parameters were more pronounced in CRF patients after hemodialysis than before hemodialysis. The findings of this study suggest the involvement of oxidative stress and trace elements in the pathogenesis of chronic kidney disease patients undergoing hemodialysis. Trace element composition of dialysis fluids may contribute significantly to disturbed trace element levels in dialysis patients. Although to a lesser extent, the possibility of acute as well as chronic intoxications of a number of trace elements other than zinc and iron also exists. Therefore, dialysate trace metal content should be checked regularly. Since both excess and deficiency of trace elements are potentially amenable to therapy, the hypothesis that trace element status influences adverse risk on clinical outcomes appears worthy of investigation. Further studies are required to evaluate the clinical significance and long term effects of imbalances of these trace elements in chronic renal failure patients on hemodialysis.

\section{References}

1. Tonelli M, Wiebe N, Hemmelgarn B, Klarenbach S, Field C, Manns B et al. Trace elements in hemodialysis patients: a systematic review and meta-analysis. BMC Medicine. 2009;7:25.

2. Meerashivashekar, William WE, Revathi R, Padmanabhan. Effect of oxidative stress in pre and post hemodialysis in chronic renal failure. 2012;1:1335-1337.

3. Krachler M, Scharfetter $\mathrm{H}$, Wirnsberger $\mathrm{G}$. kinetics of the metal cations magnesium, calcium, copper, zinc, strontium, barium and lead in chronic hemodialysis patients. Clin Nephrol. 2000;54:35-44.

4. Rajashri BB, Adinath NS, Nitin GJ. Effect of Hemodialysis on Serum Copper and Zinc Levels in Renal Failure Patients. Eur J Gen Med. 2013;10:154-157.

5. Smythe WR, Alfrey AC, Craswel PW, Crouch CA, Ibels LS, Kubo H, et al. Trace elements abnormalities in chronic uremia. Ann Intern Med. 1982;96:302-310.

6. Burtis CA, Ashwood ER, Burns DE, editors. Tietz Text Book of Clinical Chemistry and Molecular Diagnostics, 5th edition; Elsevier and Saunders: St.Louis; 2012.

7. Makino T. A sensitive, direct colorimetric assay of serum zinc using nitro-PAPS and microwell plates. Clin Chim Acta. 1991;197:209-220.

8. Hsieh YY, Shen WS, Lee LY, Wu TL, Ning HC, Sun CF. Longterm changes in trace elements in patients undergoing chronic hemodialysis. Biol Trace Elem Res. 2006;109:115-17.

9. Vanholder R, Cornelis R, Dhondt A, Lameire N. The role of trace elements in uraemic toxicity. Nephrol Dial Transplant. 2002;17:2-8.

10. Covic A, Gusbeth-Tatomir P. Trace elements in endstage renal disease - unfamiliar territory to be revealed. BMC Nephrology. 2009;10:12.

11. Krachler M, Scharfetter H, Wirnsberger GH. Kinetics of the metal cations magnesium, calcium, copper, zinc, strontium, barium, and lead in chronic hemodialysis patients. Clin Nephrol. 2000;54:35-44.

12. Kalantar-Zadeh K, Kopple JD. Trace elements and vitamins in maintenance dialysis patients. Adv Ren Replace Ther. 2000;10:170-182.

13. Guo $\mathrm{CH}$, Wang $\mathrm{CL}$, Chen PC, Yang TC. Linkage of some trace elements, peripheral blood lymphocytes, inflammation, and oxidative stress in pacients undergoing either hemodialysis or peritoneal dialysis. Perit Dial Int 2011;31:583-591.

14. Tetiker T, Paydas S, Yuregir G, Sagliker Y. Trace elements alternations in chronic hemodialysis patients with chronic renal failure and Proteinuria. Journal of Islamic Academy of Sciences. 1993;1:33-35.

15. Paydas S, Albayrak A, Yuregir G, Sagliker Y, Demirci C, Gurcay A. Trace elements in hemodialysis patients. Third international congress on Trace elements in health and Disease.1989:615.

16. Swaminathan S, Fonesca VA, Alam M.G, and Shah SV. The role of Iron in Diabetes and its complications. Diabetic Care (ADA). 2007;30:19261933.

17. Rostoker G, Griuncelli M, Loridon C et al. Hemodialysis-associated hemosiderosis in the era of erythropoiesis-stimulating agents: a MRI study. Am J Med. 2012;125: 991-999.

18. Steven F, Anna M, Nosratola DV. Iron toxicity: relevance for dialysis patients. Nephrol Dial Transplant. 2013 ;1:1093-1099. 